Session 1655

Session 1655

\title{
Looking Back: Lessons Learned from Ten Years of Training Teaching Assistants
}

\author{
Susan C. Roberts, Kathryn A. Hollar, Virleen M. Carlson \\ Cornell University
}

\begin{abstract}
Introduction
Over the past ten years, the teaching development program for engineering teaching assistants (TAs) at Cornell University has evolved from an optional lecture series run by faculty members to mandatory workshops facilitated by former engineering teaching assistants. Currently, 150200 TAs are certified each year in both a fall and spring program. This workshop series was initiated in 1987 when the numerous complaints about TAs received by the Engineering Office of Undergraduate Programs indicated a definite need for TA training. Additionally, a 1992 survey of Cornell's College of Engineering undergraduates shows that at Cornell, TAs are an important source of undergraduate instruction ${ }^{1}$. Since the program was founded, the number of complaints has become practically zero. The goals of our program have matured through the years to include not only training TAs for their specific duties, but also giving them time management skills, an understanding of University policies, and diversity awareness. Inherent in these goals is the value of teaching and the importance in uniting TAs in a teaching community. This paper gives a ten year retrospect of our program and will discuss the changes in feedback procedures, structure, program content, budget, and current initiatives as well as the lessons we have learned. Throughout the paper, participant evaluation comments that helped to shape the program will be highlighted (in italics). We hope to provide a basis for other universities to start or improve a TA development program.
\end{abstract}

\section{Feedback}

Feedback from program participants is an essential part of the TA Development Program. As we demonstrate throughout this paper, evaluation forms continue to play a major role in the evolution of the program. Feedback from TAs in the early years of the program, specifically comments on the challenges TAs encountered over the semester and their suggestions on content and timing, was instrumental in the restructuring of the program to include issues that are relevant and of practical use to TAs.

As the program has changed, feedback forms have been shortened from three pages to one page that is both qualitative and quantitative, yet can be completed in five minutes. Originally, comments were solicited on each seminar, the timing of the program, and which topics should be eliminated or added. In addition, participants were asked to evaluate their own teaching styles and share the challenges they faced. As more of the participants' suggestions on additional workshop content have been incorporated, responses to the question "which additional topics would you like to see addressed?" have dwindled, and the question was eliminated. In retrospect, removal of this question may hinder the introduction of new ideas, so re-inclusion of this question is currently being considered. The current feedback form, which has not changed significantly since 1991, includes four questions in which TAs rate (on a scale of 1-5) the value 
of the workshop, its usefulness in developing their teaching skills, how it fulfilled its stated objectives, and if it should be offered again. In addition, the form asks participants which aspects of the workshop they found most or least helpful, requests feedback specifically for the facilitators, and provides a space for more general comments. Keeping the form consistent from year to year makes comparisons easier.

During the first few years of the program, when it was a semester-long seminar/lecture series, all program feedback occurred at the end of the semester. The change from a semester-long lecture series to a workshop series held at the beginning of the semester was accompanied by a change in the timing of feedback opportunities for TAs. After several participants suggested that "you should have us evaluate the seminar immediately after the lecture instead of 2 months later, "five minutes at the end of each workshop were included for TAs to fill out a standard feedback sheet. TA self-evaluation is no longer a part of the evaluation form, since TAs complete the program within the first few weeks of the semester. TAs are instead evaluated mid-semester by their students, and results are tabulated and returned to the TA and course professor. We are currently formulating a terminal survey to be completed at the end of the semester that will address how the program influenced the TAs' experiences.

\section{Structure}

\section{Staffing}

All work is done in pairs in a co-teaching, co-directorship model. The program is currently corun by educator Dr. Virleen Carlson from the Office of Instructional Support and a Head TA Fellow who is selected from the previous year's staff. The combination of education and engineering provides the necessary perspective and a solid credibility - "It's nice to be taught by an education Ph.D. who knows what she's talking about." A staff of seven additional TA Fellows are selected each year and are assigned, along with the Head TA Fellow, as pairs to work as co-facilitators for the training workshops. The program began as a lecture series run by the engineering faculty with little involvement of graduate students, but with evaluations like, "We need more practical advice from current TAs... In general, administrative type speakers were out of touch with our concerns, "graduate students became involved as TA Fellows who could speak from recent experience and provide a less intimidating environment than faculty. Initially, the graduate student TA Fellows facilitated the workshops alone, but the program has since evolved to a co-facilitator mode. This workshop series is based on group interaction and learning from others; by bringing TA Fellows together as pairs we have been able to model teamwork in our workshops as evidenced by comments such as "You two worked very well together. You seemed comfortable with one another." Co-training in the workshops exposes the new TAs to two distinct teaching styles and different perspectives on the workshop material ${ }^{2}$. The co-facilitator approach also allows for the generation of innovative workshop ideas through discussions in the intensive TA Fellow summer training sessions ${ }^{3}$. Each year a new TA Fellow is selected to head the program along with Dr. Carlson. Despite the lack of staff continuity, the solid foundation the program was built upon and the support from the Engineering Office of Undergraduate Programs enables the program to move forward each year.

\section{Philosophy}

The program is based on interactive training in which the future TAs are able to learn in an informal environment that is conducive to group work, presentations, the asking of questions, and the sharing of ideas. Everyone learns differently, and by adapting teaching styles to incorporate various techniques in the workshops, instructors can teach more effectively ${ }^{4}$. TAs 
internalize these ideas better by discovering the answers themselves, so the job of the TA Fellow is not to lecture but to "facilitate" discussion and learning. Our goal is to encourage new TAs to implement interactive strategies in their teaching, and we demonstrate that these techniques can be successfully incorporated by modeling these strategies ourselves. The original lecture format provided virtually no group interaction, spurring responses such as "The lecture format just doesn't work. I suggest that you eliminate the lecture series." Over the ten years of the program, a balance has been achieved in the workshops to include both lecture and group interaction - "It is always enlightening to hear how other people do things."

\section{Timing of Training}

The program begins the night before classes start and is completed in three week-nights and one Saturday, ending by the tenth day of each semester. The workshops each run approximately two hours, with extra time for dinner and additional segments such as the Dean's welcome and "Do The Right Thing" (described in the content section). The first of two non-elective workshops, "Teaching Philosophy and First Class Hints" introduces new TAs to Cornell's philosophy of education and allows the TAs to develop a framework and personal philosophy for teaching. This first workshop is scheduled for the night before classes so TAs can learn "First Class Hints" before they enter the classroom. The second workshop "Teaching in a Diverse Community: Multicultural Awareness," is scheduled for one week later, and the elective workshops about specific TA duties are held on either the first or second Saturday of the semester. The current program runs about 14 hours total. The program used to run 8-9 weeks into the semester with two hours required per week. The TAs complained that they were not receiving the training they needed in time ("the sessions came too late"), so the program was gradually shortened to the structure it has today. Additionally, the academic responsibilities of both the new TAs and the TA Fellows increase as the semester progresses, so offering training at the beginning of the semester results in greater concentration and attendance. Two hour workshops seem to be the attention limit of the TAs and any attempt to lengthen a workshop resulted in many complaints, decreases in participation, and general indifference to the material.

\section{Content}

Over the years, the workshop content has changed and presently includes sessions on "Teaching Philosophy and First Class Hints," "Teaching in a Diverse Community: Multicultural Awareness," and elective workshops addressing specific TA duties such as "Leading a Recitation," "Office Hours and Tutoring," "Effective Grading," "Presentation Skills," and "Teaching in the Laboratory." This structure has remained essentially the same since 1991. In all the workshops, a sense of community is stressed as the TAs are encouraged to share their ideas and philosophies on teaching with one another throughout the program and the semester. An "icebreaker" exercise introduces each workshop and is crucial in establishing an interactive environment. This icebreaker can simply be questions like "What's the most recent movie you've seen?" or "How did your first class go?" as long as everybody gets a chance to talk.

\section{First Session}

On the first night of the program, the Engineering Dean of Undergraduate Programs welcomes the TAs to the workshop series. The Dean's welcome often elicits mixed reviews from TAs who either appreciate seeing the administration involved or believe the Dean is too preachy and condescending. However, having the Dean greet the TAs and explain Cornell's philosophy of education and teaching assistants' contribution to undergraduate instruction establishes the credibility and importance of the program. The TAs also receive a workbook that includes 
supplementary information that complements the workshops and provides a list of available resources. The workbook also includes information from all of the elective workshops for the TAs to review.

After registration and the Dean's introduction, participants are directed to smaller groups of 2030 TAs where they begin the first workshop. The purpose of this workshop is for TAs to prepare themselves mentally for their first semester of TA-ing and to encourage TAs to incorporate different strategies in their teaching. Using ideas from the Dean's introduction and their own past experiences as students, TAs are asked to formulate their own teaching philosophy. An interactive exercise introduces the disparity between learning styles and teaching styles ${ }^{4}$, motivating the TAs to think of methods they can use to reach all students. The second half of the workshop uses group brainstorming and presentations to review or introduce practical "common sense" suggestions for the TAs' first interaction with their students, including preparing a first class agenda and tools for establishing credibility.

\section{Microteaching}

The TAs must also participate in a microteaching/video recall session with three other TAs and a TA Fellow in which their teaching is videotaped, played back, and discussed. The TAs prepare a seven minute section of a lesson that mimics a typical teaching situation for them; the other three TAs are encouraged to behave as typical undergraduate students in a classroom. The goal of these microteaching sessions is to increase the confidence of the TA and guide the development of his/her teaching skills. The role of the TA Fellow in these sessions is to act as a facilitator only and not to criticize or make too many suggestions. The TA Fellow should guide the discussion in the video recall so that the TA can get past such things as "I look so awful on TV" and concentrate on the development of his/her teaching skills. We feel that the best way for TAs to improve their skills is to come up with ideas themselves and learn from their peers (the other three TAs present). The presence of the other three TAs is crucial in accomplishing this goal because they have the primary responsibility of identifying both strengths and weaknesses in the presenter's teaching style. It is the role of the facilitator to make sure that every TA is heard so that all ideas are shared. This portion of the program is consistently the highest rated component as the most valuable way to improve teaching skills; "This has been the best part of the training, I think because of all of the interaction that occurs in a 'real' teaching environment." The TAs also have the option of in-class videotaping later in the semester and a video recall with Dr. Carlson.

\section{Elective Workshops}

In the initial years of the program, questions on the evaluation form asked the TAs what topics should be added/dropped. These questions proved to be instrumental in the shaping of the program. Sessions that were dropped included "Exam Construction" and "Writing to Learn" due to numerous evaluations like: "Writing seminars were particularly ineffective" and "Forget exam construction - most TAs don't make up exams." Many evaluation comments addressed the idea that all sessions do not apply to all TAs (e.g., "This session was not useful because I do not teach lab"). Therefore, topics were placed into elective categories in which the TAs can choose the two that pertain most to them. The topics chosen for the elective workshops are now "more specific to the type of TA roles" the new TAs will assume. Currently, TAs can select two of four elective workshops on "Grading," "Office Hours and Tutoring," "Leading a Recitation," and "Teaching in a Laboratory." 
Several features have been added to the elective program day over the last couple of years in response to TA evaluations. An all-day advanced TA-ing session has been added to replace the two Saturday elective sessions for TAs who feel they already have extensive teaching experience. They fill out an application that has them list questions that demonstrate their level of involvement or thinking about teaching. Dr. Virleen Carlson reviews the applications and selects approximately ten students to join her for advanced TA instruction designed around the questions the TAs have identified on their application. This session has received an overwhelmingly positive response and in fact has encouraged advanced TA-ing participants to meet outside the program to further discuss teaching issues. A segment called "Do The Right Thing" has also been added at the start of the day, and focuses on ways TAs can protect themselves both legally and personally while addressing TA concerns like "academic integrity and ways of detecting cheating." The TA fellows give short consecutive presentations (five minutes each) on safety, student privacy, copyright laws, academic integrity, sexual harassment, and "looking out for number one." This segment highlights academic policy and identifies the resources available to TAs if an unpleasant situation should occur in their teaching (e.g., student cheating or sexual harassment).

Teaching in a Diverse Community

Many TAs wanted to know more about "human relations," how to "deal with foreign students," or the "cultural differences between men and women in the classroom and how to deal with it." A workshop on multiculturalism was added to the program, not out of political correctness, but rather as a direct response to TA evaluations. This workshop has evolved into one of the most important parts of the workshop series. For some ideas about what to include in a workshop about multiculturalism see Eschenbach et $\mathrm{al}^{5}$. The TA Fellows receive extensive multicultural training in their summer training program to prepare them to discuss diversity with the new TAs. The workshop takes on a slightly different form every year in the hopes of making it more appealing; however, many TAs still reject the idea of diversity training and cannot understand how such training can enhance their teaching skills. With the help of evaluations, we have focused the workshop around factual case studies written by the TA Fellows from their own teaching experience. The facilitators encourage discussion from the group as to what actually happened, how to handle the situation, and how it could have been avoided. The factual nature of the case studies adds tremendous credibility to the workshop while eliminating comments such as "case studies were too remote to be realistic." We have also added a stage performance by the Cornell Interactive Theatre Ensemble (CITE) entitled "Hang in There and Be Tough" that addresses the concerns of a female student who is not getting the respect of her male peers or professor and turns to her TA for support. The TA is in a dilemma because his advisor is the professor of the course and he subtly acts unsupportive towards the student. The situation is realistic and addresses TAs concerns about "...dealing with professors. TAs are caught in the middle and could use help." This performance stimulates passionate discussion and provides an excellent medium for the sharing of ideas and opinions. It is also important to include some statistical reasoning for the need for diversity training (particularly for engineers), and we have included this by showing Cornell engineering demographics and graduation/attrition statistics for minority students. We also include a study on the astonishing differences in the self-assessment of equally intelligent men and women in educational institutions ${ }^{6}$. It is vital to impart a commitment to diversity to the TAs, because it is highly unlikely the TAs will have another opportunity to receive this type of training. 
Strategies for Interactive Workshops

It was briefly mentioned in the above paragraph the effectiveness of case studies in not only bringing out ideas and answering questions, but preparing TAs for what they might encounter in their teaching experiences. Many TAs wanted workshops on "problems TAs encounter, or how to deal with: oppressive professors, arrogant students, stressed out students..." and in response we have incorporated some variation of case studies into every workshop. In reply to evaluations like "the best part of this workshop was suggestions from TA Fellow experts" and "put in more personal experiences within the subject and how you handled it," we have added question and answer sessions at the appropriate times in some workshops and shared our experiences at other times. To balance out the discussion component of the program, TAs are given opportunities to develop specific skills by actually presenting, tutoring, or grading mock problems during each workshop; "Practice is what counts." Some interactive strategies we have found successful are outlined below.

1. Icebreakers are designed to relax the group and establish an informal atmosphere. Some icebreakers have themes related to workshop topic, such as using a beach ball globe in the multicultural workshop, while others are designed just to let participants get to know each other better.

2. Brainstorming is used to introduce topics, usually at the beginning of workshops. A 5-10 minute brainstorming session sets the tone for an interactive workshop by allowing the TAs to express their ideas. These segments also give facilitators a feel for which TAs are outspoken or reserved.

3. Small group discussions of 5-15 minutes give all TAs a chance to participate, even those who feel nervous speaking in front of a large group. Each group of 2-5 is asked to discuss and write down their thoughts on particular case studies or questions posed by the facilitators. One or two group members are then asked to share conclusions with other participants.

4. Participants present short segments based on small group discussions. Each small group is asked to select a speaker, preferably someone who does not have public speaking experience. A facilitator may suggest a speaker from a group if he or she has noticed a lack of participation from that TA.

5. Group exercises give TAs a chance to practice specific skills like tutoring, grading, and lab instruction. In tutoring and lab instruction exercises, TAs in groups of three take turns acting as teacher, student, or observer. The observer initiates discussion based on an observation checklist, and each group member shares their perception of how the TA has performed. One of our most successful exercises is the "grading game," in which each group of 5 is given the same engineering homework problem with 5 different student solutions. Each group has to determine grading criteria, then each member of the group corrects one solution following the set criteria. Groups are then reorganized according to student solution number. Every time we have facilitated this exercise, we have seen disparities of at least 50 points between TAs for the same homework solution. This exercise is an excellent way to point out inconsistencies in grading and emphasizes the importance of developing uniform grading methods before homework assignments or exams are graded. 
Small group exercises are not "rest time" for the facilitators. Facilitators must perform several tasks simultaneously, including focusing group discussions, encouraging participation from all TAs, clarifying questions, and keeping segments on time.

\section{Budget}

Initially the program budget was minimal, covering only copying and presentation costs with faculty volunteers and TA Fellows left unpaid. As the program expanded and more TAs were trained by the program, the budget increased accordingly and pay was included for the leaders in order to reflect fairly the time commitment involved. The program currently costs roughly $\$ 50,000$, is funded through the Office of Undergraduate Programs and includes food, workbook costs, TA Fellow salaries $(\$ 1,400$ each), Head TA Fellow salary and tuition support $(\$ 30,000)$, video equipment upgrades, and conference stipends. It is important to include funding for conferences in the budget in order to give the program, school, and the TA Fellow exposure. An issue that needs to be considered when initiating a TA training program is start-up costs (i.e., paying someone to develop the program from scratch and purchasing the necessary video equipment).

\section{Current Initiatives}

We constantly strive to improve the program by incorporating new ideas and increasing support. Recently we have been initiating more contact with the individual engineering departments due to TA attendance and motivation problems. Over the years, faculty involvement has become almost non-existent and although the workshops are no longer run by the faculty, it is important to get their enthusiastic, verbal support for the program. There is often a problem motivating TAs to attend a mandatory training program and the increased involvement/support of faculty may help to alleviate this problem. Extending the depth and breadth of communication between the program, faculty, and TAs is a principal goal for the upcoming year. In addition, due to the success of the program, the Office of Undergraduate Programs has begun to solicit support for an endowment fund from outside sources. We are also developing a terminal feedback survey to be distributed to TAs at the end of the semester that will indicate the usefulness of the training program in their teaching experience.

\section{Conclusions: Lessons Learned}

Over the past ten years, the Engineering TA Development Program at Cornell has grown into a mandatory, well-supported program for all engineering TAs. The success of the program is a result of foresight and continued self-evaluation. Some of the lessons we have learned over the years are:

1. Have a vision of where the program should be in five or ten years. Vision is important not only at the inception of the program but as it grows and evolves. Every year we look forward, making changes based on the needs and comments of our audience, but we also periodically look back at where the program has been. A global self-evaluation every five years ${ }^{7}$ gives us an idea of how challenges were faced in the past, reminds us to plan for future challenges, and is essential for the success and continuity of the program.

2. Identify concerns of the target audience (TAs). As we have demonstrated throughout this paper, our program has been built on suggestions and comments of participants. This commitment to incorporating the ideas of participants gives the program credibility, focuses the workshops on relevant topics, and makes TAs more receptive to training. 
3. Keep consistent, thorough records from the beginning. Our program experienced a complete staff turnover a few years ago, yet continued to run smoothly and grew even more. The program maintained its continuity because good record-keeping was incorporated into the original vision. Program evaluation is not possible without past records, so our workshop successes and failures are documented and summarized every semester.

4. Have the power to make needed modifications. Depth and breadth of support and communication empower the program to improve itself. The program's administrative and staffing structure involves elements across the University, from the Office of Instructional Support, to the Dean of Undergraduate Programs in Engineering, to TA Fellows from various engineering departments. As we continue to improve communication between the program and the different engineering departments, we anticipate greater support and more motivated participants.

5. Provide a structured but relaxed atmosphere. Stick to a published schedule, provide a balance of lecture and interaction, reserve comfortable rooms, plan for a small workshop size (20-25 people), and provide food. One of the goals of the program is to establish teaching as a community. Seemingly minor details in a program, such as providing air conditioning, having a vegetarian entree choice for dinner, or being called by name, can affect participants' attitudes. For example, supplying meals encourages socializing, and we have found that some of the most stimulating conversations about teaching occur during lunch or dinner breaks.

6. Give TAs some choice in which workshops to attend. At Cornell, TA training is mandatory in the College of Engineering to insure that all TAs are well-prepared, from those who are enthusiastic about teaching to graduate students who view TA-ing as a necessary evil. TAs are becoming a more diverse audience with different levels of experience and often contradictory ideas about what is important in teaching (or even if teaching is important). Motivating every person is a Herculean task, but we try by balancing general information workshops with workshops dealing with specific duties and individualized attention (e.g., microteaching).

7. Offer program segments in a timely fashion. After the first two weeks of the semester, the TA's duties and the relationship between the TA and his/her students have been established. Giving TAs the opportunity to think about and prepare for challenges before they encounter their students allows them to make informed decisions and avoid sticky situations. Also, TAs are less busy at the beginning of the semester and can concentrate more on their teaching development. Feedback from participants' students occurs mid-semester so the TAs can focus on areas that need improvement before the semester is over.

8. Use a valuable resource: graduate students who are enthusiastic about teaching. Appointing TA Fellows from the pool of TAs who complete the program establishes credibility by showing that someone who has recently participated in the program has benefited and is using the skills they learned. Graduate TA Fellows contribute to vision by infusing new ideas and energy every year. Additionally, TA Fellow training is global and extensive, so the program can be recreated by any of the TA Fellows at another university. 


\section{References}

1. Improving the Freshman-Sophomore Engineering Educational Experience, Report of the Ad Hoc Committee for Improving the Freshman-Sophomore Engineering Educational Experience, College of Engineering, Cornell University, December 15, 1992.

2. Miller, Gerald V., and Patricia G. Wilson, Co-Training: A Synergistic Outcome, Training and Development Journal, September, 1982.

3. Jacobs, Jennifer and Elizabeth A. Eschenbach, Educating the Next Generation of Engineering Professors: Cornell's Teaching Fellow Program, ASEE Annual Conference Proceedings, 1996.

4. Felder, Richard M., and Linda K. Silverman, Learning and Teaching Styles in Engineering Education, Engineering Education, April, 1988.

5. Eschenbach, Elizabeth A., Taylor, Martha B., and Rodney J. Parrott, Teaching in a Diverse Community: Multicultural Awareness, ASEE Annual Conference Proceedings, 1994.

6. Widnall, Sheila E., AAAS Presidential Lecture: Voices from the Pipeline, Association Affairs, September 30, 1988.

7. Eschenbach, Elizabeth A., Taylor, Martha, and Gerald Rehkugler, Implementing a Teaching Assistant Development Program with Continuous Improvement, ASEE Annual Conference Proceedings, 1993.

\section{Biographical Information}

SUSAN C. ROBERTS, the 96-97 Head TA Fellow for the TA Development Program, graduated with high distinction with her B.S. in chemical engineering from Worcester Polytechnic Institute in 1992. She is currently a Ph.D. candidate in chemical engineering at Cornell University supported by fellowships from the DOD and AAUW. Susan expects to graduate in December 1997 and plans to enter academia in chemical engineering.

KATHRYN A. HOLLAR, the 97-98 Head TA Fellow for the TA Development Program, graduated summa cum laude from North Carolina State University in 1993 with B.S. degrees in chemical engineering and English. She is currently a Ph.D. candidate in chemical engineering at Cornell University supported by an NSF Fellowship.

VIRLEEN M. CARLSON, Ph.D., is the Assistant Director of the Office of Instructional Support, Cornell University. Although part of centralized administration, her appointment is the equivalent of one-fifth time in the Engineering College as co-coordinator of the TA Development Program. With 21 years in the field of education and a Ph.D. in Curriculum and Instruction, she provides the Education background for the program and its facilitators. 